\title{
Perovskite oxides as electrocatalyst for glycerol oxidation.
}

\author{
Patricia V.B. Santiago ${ }^{\mathrm{a}, \mathrm{b}, \mathrm{c}}$, Carlos C. Lima ${ }^{\mathrm{b}, \mathrm{c}}$, José L. Bott-Neto ${ }^{\mathrm{b}, \mathrm{c}}$, Pablo S. Fernández ${ }^{\mathrm{b}, \mathrm{c}}$, Camilo A. An- \\ gelucci ${ }^{\mathrm{a}}$, Janaina Souza-Garcia ${ }^{\mathrm{a}}$
}

\author{
${ }^{a}$ Federal University of ABC, Av. dos Estados 5001, 09210-580, Santo André SP, Brazil. \\ ${ }^{\mathrm{b}}$ Chemistry Institute, State University of Campinas, PO Box 6154, 13083-970, Campinas SP, Brazil. \\ ${ }^{c}$ Center for Innovation on New Energies, University of Campinas, CEP 13083-841 Campinas, SP, Brazil.
}

\begin{abstract}
Glycerol is a co-product from Biodiesel production with high abundance and low market price. Its transformation into valuable products or as an alternative source of energy has driven the search for selective catalysts. Herein we present the first findings of perovskites as electrocatalysts for glycerol electrooxidation (GEOR). Alternatively to $\mathrm{Pt}$ and $\mathrm{Pd}$ based catalyst, perovskite oxides $\left(\mathrm{LaNiO}{ }_{3}\right.$ and $\mathrm{LaCoO}_{3}$ ) demonstrated high catalytic performance with faradaic currents of ca. $18 \mathrm{~mA} \mathrm{mg}{ }^{-1}$ at potentials higher than $1.6 \mathrm{~V}$ vs. RHE. Consecutive potential cycles exhibited the $\mathrm{LaCoO}_{3}$ perovskite resistant to poisoning during GEOR. Based on FTIR and online HPLC experiments the GEOR on perovskite oxides yields formic acid and glycolic acid as final products, with no signal of $\mathrm{CO}_{2}$ formation. Our results thus indicate that perovskites can be considered as an alternative for selectively oxidize glycerol, opening the door for a large variety of a new class of catalysts for polyols oxidation with efficiency in terms of current densities and poisoning stability.
\end{abstract}

.KEYWORDS. Glycerol Electrooxidation Reaction, Perovskites, in situ FTIR, online HPLC.

\section{INTRODUCTION}

An intensive investigation for more sustainable energy sources has bloomed in recent years. With the increase of global population, it is mandatory to develop new strategies to allow sustainable industrial and technological development whilst protecting the environment. In this scenario, the use of non-fossil fuels has been encouraged. Biofuels, such as ethanol and biodiesel, have been used as alternatives to fossil fuels for decades. At the same time, hydrogen has been considered one of the main alternatives to address energy issues allowing technological innovation. However, its major production route pass through the use of fossil fuel by processes that are not environment friendly. ${ }^{1}$

The production of glycerol, a co-product from biodiesel manufacture, has increased due to biodiesel production incentive, lowering its price in global market. Although glycerol is a versatile product with practical use in several industries, such as personal care, household products, plastics, fragrances, foods and pharmaceutics, its production is still much higher than the actual consumption. Therefore, scientists have been evaluating its use for new applications at current chemical industries, as well as for the generation of energy in fuel cells and the concomitant production of high added value glycerol derivatives and hydrogen in electrolyzers. ${ }^{2-5}$ Considering the use in fuel cell, besides the demands for membrane improvement, it is mandatory to develop low cost electrocatalysts able to reduce the overpotential and tune the selectivity of the glycerol electrooxidation reaction.

Traditionally, noble metals as $\mathrm{Pt}, \mathrm{Au}$ and $\mathrm{Ag}$ as well as $\mathrm{Pd}, \mathrm{Bi}, \mathrm{Rh}$ are the main studied materials ${ }^{6-10}$ showing catalytic performance, with good currents, some selectivity but with a very high cost. Thus, it is of great importance to develop new catalyst based on abundant and no-expensive materials.

No-noble metals as $\mathrm{Ni}, \mathrm{Cu}$ and $\mathrm{Co}$ have also presented activity as catalysts for alcohol oxidation ${ }^{11-15}$. Some results have indicated that the addition of transition metal oxides to $\mathrm{Pd}$ and Pt catalysts can contribute to enhance its alcohol oxidation ability. ${ }^{16,17}$

An alternative would be perovskite like materials. It is possible to use no-noble metals and rare earth in their composition, which are less costly materials than traditional catalysts as platinum and gold. There are several studies in the literature, considering perovskite oxides as catalysts for heterogeneous catalysis, photocatalysis, as well as electrocatalysis ${ }^{18-23}$. In heterogeneous catalysis different perovskites have been studied for $\mathrm{CO}$ and hydrocarbons oxidation, ${ }^{24-26} \mathrm{NO}_{\mathrm{x}}$ decomposition, ${ }^{27-29}$ hydrogenation of carbon oxides $^{30,31}$ and glycerol reforming ${ }^{32,33}$. As electrocatalyst, good results for oxygen evolution reaction (OER), and oxygen reduction reaction (ORR), have also been reported with $\mathrm{LaMnO}_{3}, \mathrm{LaCoO}_{3}$ and $\mathrm{LaNiO}_{3} .{ }^{34-37}$

Many studies regarding the role of the transition metals, have been done. The relationship between the electrocatalyst activity and the electron occupancy of anti-bonding orbitals of $\mathrm{M}-\mathrm{OH},{ }^{34}$ metal electronegativity, ${ }^{38}$ oxygen vacancy ${ }^{39}$ and perovskite defects ${ }^{40}$ have been investigated. All these works have demonstrated that the element substitution at both positions of perovskite structure can largely impact the properties of the material. Hardin et al. ${ }^{41}$ investigated the influence of the transition metal used to tune the catalyst for the OER and ORR. They proposed an electrocatalyst based on $\mathrm{LaCoO}_{3} / \mathrm{NC}$ which presented a 3 times higher activity for OER and ORR when compared to $\mathrm{IrO}_{2}$ (a benchmark catalyst) ${ }^{42,43}$. Also, $\mathrm{LaNi}_{0.75} \mathrm{Fe}_{0.25} \mathrm{O}_{3} / \mathrm{NC}$ demonstrated to have an activity for ORR comparable to $\mathrm{Pd} / \mathrm{VC}$.

In heterogeneous catalysis, perovskites have been investigated as catalysts towards ethanol and methanol combustion ${ }^{44}$. Different perovskites for methanol combustion have been studied and their activity was reported to be associated to the concentration of $\alpha$-oxygen and metal sites with high oxidation state. Lan and Mukasyan ${ }^{45}$ have investigated the use of different perovskites based on $\mathrm{Ru}$ as support for Pt nanoparticles as electrocatalysts. They reported a material with activity comparable to Pt-Ru alloy but containing 4 times less platinum for methanol oxidation at direct methanol fuel cell (DMFC).

Since $\mathrm{LaNiO}_{3}$ and $\mathrm{LaCoO}_{3}$ perovskites have demonstrated activity towards glycerol reforming ${ }^{46}$ and oxygen evolution reaction (OER), ${ }^{34}$ the goal of tis work was to investigate the activity of these catalysts for glycerol electrooxidation reaction (GEOR). The physical and electrochemical characterizations of the catalysts are 
presented, as well as their activity for GEOR and a reaction pathway study supported by in situ FTIR and online HPLC results.

\section{EXPERIMENTAL SECTION}

Chemicals.

The reagents used in this work were purchased from Sigma-Aldrich, namely: $\mathrm{La}\left(\mathrm{NO}_{3}\right)_{3} \cdot 6 \mathrm{H}_{2} \mathrm{O} \quad(99.9 \%), \quad \mathrm{Ni}\left(\mathrm{NO}_{3}\right)_{2} \cdot 6 \mathrm{H}_{2} \mathrm{O}$ (99.999\%), $\mathrm{Co}\left(\mathrm{NO}_{3}\right)_{2} .6 \mathrm{H}_{2} \mathrm{O}(>98 \%)$, citric acid (99\%), ethylene glycol $(99.8 \%)$ and glycerol $(99.8 \%)$. Formic Acid (85\%) from Synth, Glycolic acid (70\%) from Chemours and $\mathrm{NaOH}(99 \%)$ from Isofar.

\section{Material Synthesis}

The synthesis methodology was chosen with the objective to obtain a good perovskite formation rate, higher surface area and shorter reaction time. In this way, two methodologies were combined, and the perovskites were produced by citrate method ${ }^{47}$ assisted by microwave. ${ }^{48,49}$

Lanthanum and the transition metal ( $\mathrm{Ni}$ or $\mathrm{Co}$ ) nitrates were mixed in a beaker and a minimum volume of water was added to solubilize the salts. The mass of nitrates was stoichiometrically calculated from the amount of perovskite wished to be produced. When a homogenous mixture was obtained, citric acid was added in a molar ratio of 1:1 (citric acid:metal). The solution was mixed until the complete solubilization of reactants. Then, ethylene glycol (EG) was added at a ratio of 2.5:1 (EG:metal). The final solution was heated for 10 minutes at $60 \%$ of total power in a conventional microwave (Panasonic Style NN-ST652W (2450 MHz and $1650 \mathrm{~W})$ ). At this stage, the solution was converted to a dry foam with a large volume. The foam was broken into a powder and dried at $110^{\circ} \mathrm{C}$ for 24 hours. Once the powder was dry, the material was calcinated using a vertical tubular oven Sanchis at $600^{\circ} \mathrm{C}$ in an oxidant atmosphere (synthetic air) for 3 hours to form the oxides. Finally, the material was calcinated at $900^{\circ} \mathrm{C}$ for 10 hours, with a synthetic air atmosphere to guarantee the oxygen supply and the solid-state reaction to form the perovskite oxide.

\section{Material Characterization}

The materials were characterized by X-ray diffraction (XRD) using a STOE STADI $P$ with a molybdenum source and a germanium (111) monochromator in transmission mode. The samples were binned into a quartz tube, in powder form, and scanned from $2^{\circ}$ to $60^{\circ}$ in a step-scan mode with step-size of $0.015^{\circ}$ and counting time of $100 \mathrm{~s}$ (at each $0.78^{\circ}$ ) for $\mathrm{LaNiO}_{3}$ and $20 \mathrm{~s}$ (at each $0.78^{\circ}$ ) for La$\mathrm{CoO}_{3}$ in order to obtain a spectrum with a good resolution.

Catalysts images and EDS results were collected with a Scanning Electron Microscope (SEM) FESEM JMS-6701F, JEOL. Samples were prepared by adding a drop of perovskite dispersed in water on the surface of a carbon tape attached to a brass stub. The perovskite dispersion was obtained after 9 hours in the ultrasound bath. The drop was dried at $60^{\circ} \mathrm{C}$ for 10 minutes.

\section{Electrochemical Characterization}

Glycerol electrooxidation was investigated by cyclic voltammetry technique. A NaOH $0.1 \mathrm{molL}^{-1}$ solution was used as support electrolyte. Before electrochemical experiments, the electrolyte was deoxygenated by argon (Ar 5.0 White Martins), which was also used to keep the cell atmosphere free from oxygen during the experiment. The alcohol solution, in a concentration of $0.1 \mathrm{molL}^{-1}$, was prepared by mixing the electrolyte solution with the calculated amount of glycerol.
The perovskites suspensions were prepared by adding $0.03 \mathrm{~g}$ of the material to $1 \mathrm{~mL}$ of ultrapure water and dispersing in ultrasound (Eco-Sonics Ultronique Q3.0/40A of $40 \mathrm{kHz}$ ) for 9 hours. The influence of ultrasound time in voltammetric profile will be explained later.

The analysis was carried out in a traditional three electrode glass cell. The working electrode (WE) was prepared by depositing the catalyst dispersion on the surface of a polished glassy carbon electrode (GC). The electrode was dried for 10 minutes at $60^{\circ} \mathrm{C}$, transferred to the electrochemical cell and a voltammetric profile was registered in the electrolyte solution.

A platinum wire, with a high superficial area, was used as counter electrode (CE). A reversible hydrogen electrode (RHE) was used as reference electrode and all the results are presented against it. A potentiostat Autolab PGSTAT $128 \mathrm{~N}$ connected to a computer was used during the electrochemical experiments. The presented currents were normalized by catalyst mass.

\section{In situ FTIR}

A Shimadzu Prestige-21 spectrometer equipped with a mercury cadmium telluride (MCT) detector was used. The spectra were obtained during chronoamperometry measurements (from 0.8 to $1.8 \mathrm{~V}$ versus RHE) in a three electrode spectroelectrochemical cell with $\mathrm{CaF}_{2}$ window attached to the bottom. Working electrode was prepared as described during GEOR evaluation. The working electrode was carefully pressed against the $\mathrm{CaF}_{2}$ window, resulting in the formation of a thin layer of about $1-10 \mu \mathrm{m}^{50}$. Fourier transform infrared spectroscopy (FTIR) spectra were composed by 256 interferograms with a resolution of $4 \mathrm{~cm}^{-1}$, with the electrode potential modulated between E1 (sample potential) e E2 (background potential, $0.8 \mathrm{~V}$ vs. RHE).

Online sample collection and High-performance liquid chromatography (HPLC)

Samples were collected by a tube placed very close to the electrode surface connected to an automated collector with a robotic arm that pours aliquots into Eppendorf vials during a linear potential sweep between $0.8 \mathrm{~V}$ and $1.8 \mathrm{~V}$ at $1 \mathrm{mVs}^{-1}$. Aliquots of $60 \mu \mathrm{L}$ were collected with a flow rate of $1 \mu \mathrm{Ls}^{-1}$. Thus, each collected sample represents the products of GEOR generated in an interval of $60 \mathrm{mV}$. Each Eppendorf contained $20 \mu \mathrm{L}$ of a $0.6 \mathrm{molL}^{-1} \mathrm{H}_{2} \mathrm{SO}_{4}$ solution to acidify the sample and avoid further chemical reactions of some glycerol oxidation products. Some products, such as dihydroxyacetone, are not stable in alkaline medium so the sample acidification can avoid product degradation and ensure its identification. ${ }^{51}$ The collected samples . were analysed in a Shimadzu LC-6AD chromatograph with a quaternary pump, a thermostatic column compartment CTO-20A kept three columns (an Aminex HPX87-H and two Shodex Sugar SH1011 with a Bio-Rad 1250131 precolumn) at $85^{\circ} \mathrm{C}$. An UV-vis (SPD-20AV at 205 and $254 \mathrm{~nm}$ ), and a refractory index (RID-20A) were used as detectors, both kept at $40^{\circ} \mathrm{C}$. A $5 \mathrm{mmolL}^{-1}$ aqueous sulfuric acid solution was used as eluent with a flow rate of $0.6 \mathrm{mLmin}^{-1}$. Finally, the detected products were identified by comparison with standard samples.

A calibration curve for formate, tartronate, glycerate, glyceraldehyde and glycolate can be seen in Figure S1 of the Supporting Information (SI). Solutions containing all the substances with 5 different concentrations between 0.006 and $0.8 \mathrm{molL}^{-1}$ were prepared in $0.1 \mathrm{molL}^{-1} \mathrm{NaOH}$ and acidified with $\mathrm{H}_{2} \mathrm{SO}_{4}$ before analysis, using the same procedure described before for the collected samples during the electrochemical experiment. 


\section{RESULTS AND DISCUSSION}

\section{Electrocatalyst Characterization.}

XRD patterns were recorded to characterize the bulk crystallographic structure of the perovskites (Figure 1). Both materials were characterized based on the Crystallography Open Database (COD) and Inorganic Crystal Structure Database (ICSD).

For $\mathrm{LaNiO}_{3}$ the corresponding diffractogram (see Figure 1(a)) matches with $\mathrm{LaNiO}_{3}$ pattern, however it also presents an additional peak corresponding to nickel oxide $(\mathrm{NiO})$. Such presence is an indicative that not all the nickel precursor was converted into the perovskite structure. Retuerto et al. have observed the presence of a $\mathrm{NiO}$ phase with $\mathrm{LaNiO}_{3}$ and its dependence on the synthesis methodology, specially the calcination temperature. ${ }^{52}$ On the other hand, the diffractogram for $\mathrm{LaCoO}_{3}$ (Figure 1(b)) do not show the presence of another phase, indicating the formation of a pure material.

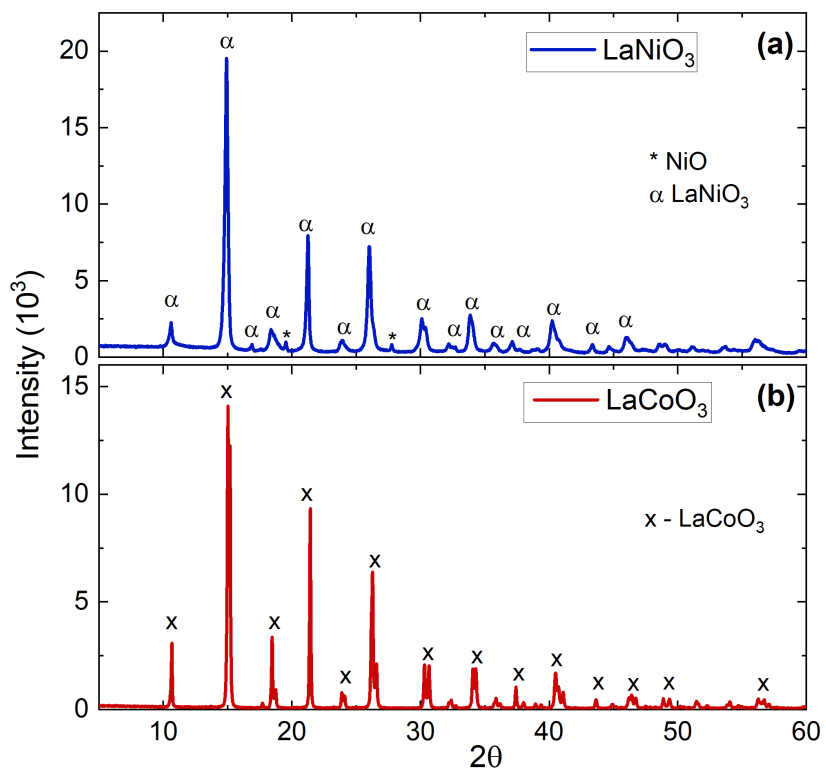

Figure 1: XRD for the synthesized materials (a) $\mathrm{LaNiO}_{3}$ and (b) $\mathrm{LaCoO}_{3}$. The standard $2 \theta$ are indicated by $(\alpha) \mathrm{LaNiO}_{3}$ (ICSD 67717), (*) $\mathrm{NiO}$ (COD 00-432-9323) and (x) $\mathrm{LaCoO}_{3}$ (COD 00153-3633)

SEM images (see Figure S2) of $\mathrm{LaNiO}_{3}$ and $\mathrm{LaCoO}_{3}$ show that the general appearance and element dispersion through the sample are similar for both materials. A granular heterogeneous distribution of particles with size that range from few micrometers to $100 \mu \mathrm{m}$ are observed regardless the catalyst composition. Additionally, the EDS analysis showed that (see insets in Figure S2) all the components are homogenously distributed in the analyzed areas and no agglomeration of a specific element is observed in either samples.

\section{Electrochemical Experiments}

The cyclic voltammograms of $\mathrm{LaNiO}_{3}$ in the presence and absence of glycerol are displayed in Figure 2. The stationary cyclic voltammogram in the supporting electrolyte exhibits a large potential window, between $0.6 \mathrm{~V}$ and $0.9 \mathrm{~V}$, with no faradaic current, establishing an electrical double layer feature (Figure 2(a)). During the positive scan a single oxidation peak centered at $1.48 \mathrm{~V}$ (i) arises followed by the begging of the oxygen evolution reaction (ii). In the negative scan a reduction peak at $1.28 \mathrm{~V}$ (iv) with a small shoulder at $1.37 \mathrm{~V}$ (iii) can be seen. The clear-cut assignment of each described peak to a surface process is not straightforward for perovskites materials. The presence of at least two metal centers that could interact with the electrolyte brings additional difficulties to the assignment. For the materials here studied the electrochemical literature is scarce and there is a lack of information about the relation between the surficial structure of the perovskite oxide and its corresponding cyclic voltammogram profiles. In this way, we have used the similarity with the CV profile of Ni metal electrodes to get further insights about our results.

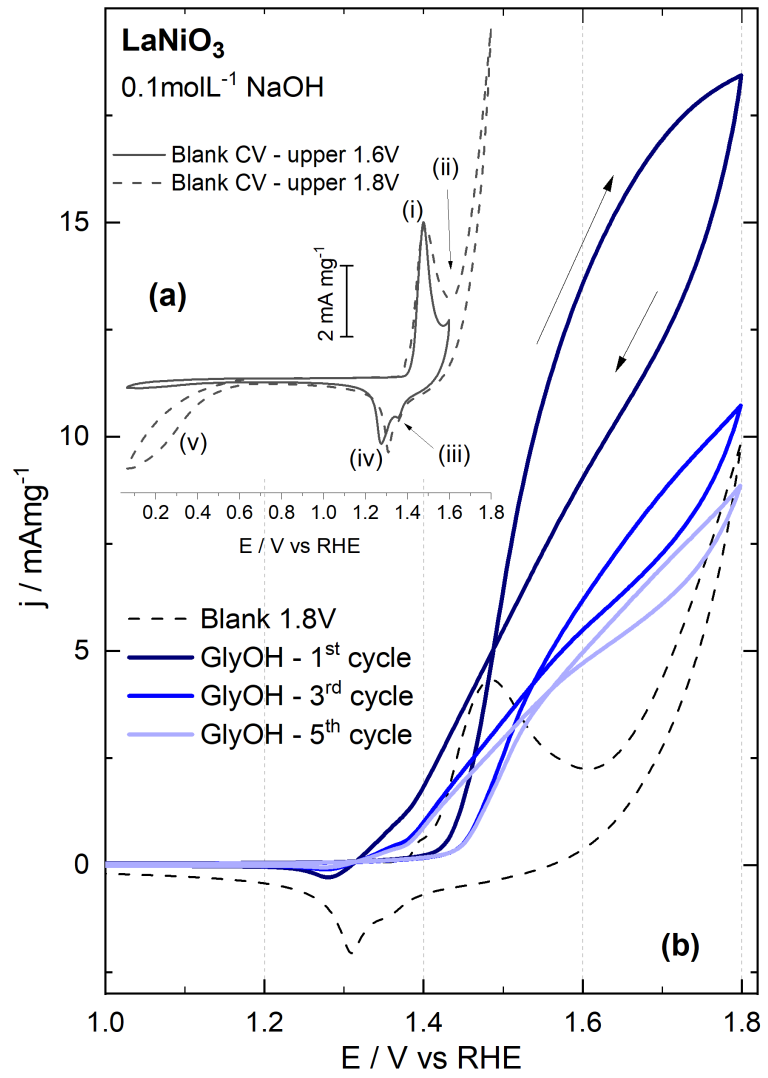

Figure 2: Voltammetric profile for $\mathrm{LaNiO}_{3}$ in the absence (a) and in the presence (b) of $0.1 \mathrm{molL}^{-1}$ glycerol in $0.1 \mathrm{molL}^{-1} \mathrm{NaOH}$ at $50 \mathrm{mVs}^{-1}$. (a) Blank voltammograms with different upper potentials: $1.6 \mathrm{~V}$ (solid line) and 1.8 V (dashed line). (b) Dash line shows the profile in the absence of glycerol and solid lines the $1^{\text {st }}, 3^{\text {rd }}$ and $5^{\text {th }}$ cycles of glycerol oxidation. Currents normalized by catalyst mass. Ohmic correction was applied.

The voltammetric profile of $\mathrm{Ni} / \mathrm{C}$ nanoparticles in alkaline media suggests that the main electrochemical process seen for $\mathrm{LaNiO}_{3}$ (Figure 2(a)) is related to the formation of surface nickel hydroxides and oxides. ${ }^{53-55}$ For a nickel metallic electrode, it has been reported that, at lower potentials, the metallic species are firstly oxidized to a highly hydrated nickel hydroxy $\left(\alpha-\mathrm{Ni}(\mathrm{OH})_{2}\right)$. As the potential is made more positive this species becomes a less hydrated hydroxy $\left(\beta-\mathrm{Ni}(\mathrm{OH})_{2}\right)$, which is considered more stable. Once it is formed, it accumulates on the electrode surface. As the potential is made more and more positive, $\beta-\mathrm{Ni}(\mathrm{OH})_{2}$ is oxidized to form a $\beta$ $\mathrm{NiOOH}$ and further $\gamma-\mathrm{NiOOH}$. In the negative scan it is possible to identify a reduction peak related to the reduction of $\mathrm{Ni}$ (III) to $\mathrm{Ni}$ (II), in the form of $\beta-\mathrm{Ni}(\mathrm{OH})_{2}{ }^{54}$

During these processes, different types of oxide populations are formed on the surface of the electrode what can explain the broad oxidation and reduction peaks. This can also explain the presence of a small shoulder during the negative scan due to the reduction of the multitude of nickel oxides that were formed, as demonstrated by El-Shafei et al. ${ }^{56}$ Different ratio between the shoulder and the 
main reduction peak were observed, indicating that the reduction process taking place between $1.5 \mathrm{~V}$ and $1.1 \mathrm{~V}$ is related to the reduction of different oxide species. Considering the results for $\mathrm{LaNiO}_{3}$ (Figure 2(a)), the peak at $1.48 \mathrm{~V}$ (i), during positive scan, may correspond to the formation of $\mathrm{NiOOH}$ on the electrode surface, while the peak at $1.28 \mathrm{~V}$ (iv), during negative scan, is related to the oxygen-hydroxy reduction to $\beta-\mathrm{Ni}(\mathrm{OH})_{2}$. Moreover, at potentials higher than $1.55 \mathrm{~V}$ the oxygen evolution process begins (ii). When the upper potential is increased the current increases accordingly. Concomitantly, the formation of bubbles on the electrode surface is observed. The oxygen formed is then reduced during the negative scan as observed by the appearance of a reductive current starting from $0.6 \mathrm{~V}(\mathrm{v})$. These features confirm that the process (ii) is actually the onset of the process related to oxygen evolution. The ability to catalyze the oxygen reduction reaction (ORR) has already been reported for $\mathrm{LaNiO}_{3} .{ }^{34,41,57}$

When glycerol is added to the electrochemical system (Figure 2(b)) the $\mathrm{CV}$ profile changes considerably indicating the ability of $\mathrm{LaNiO}_{3}$ to catalyze glycerol oxidation. To date, however, no studies of glycerol electrooxidation (GEOR) on $\mathrm{LaNiO}_{3}$ has been reported in the literature. The consecutive CVs of GEOR show that the reaction does not take place at potentials below ca. $1.38 \mathrm{~V}$. From this potential on the current related to glycerol oxidation rises steeply until it reaches the upper potential limited to $1.8 \mathrm{~V}$. During the reverse scan, the current profile continuously decreases until $1.3 \mathrm{~V}$, where the GEOR ceases. Considering the extent of the hysteresis related to the formation of strongly adsorbed intermediates, 10,58 the coverage of adsorbed species that remains on surface during the positive scan is different from that produced during the negative one. In this case, the stripping of the strongly adsorbed species is deeply correlated to the scan direction and consequently the origin of such behavior indicates that alcohol oxidation process starts only when $\mathrm{NiOOH}$ species is formed concomitantly on the electrode surface. The need of oxygen-containing specie for alcohol oxidation is a common place in the electrocatalysis of small alcohols. ${ }^{9}$ The GEOR process remains at potentials where the Nihydroxides is favorable formed. It is worth mentioning that the Nihydroxides formation is greatly influenced by the GEOR process once the oxygen evolution is suppressed in the presence of glycerol. Additionally, no bubbles were observed on electrode surface nor ORR current during the negative scan (see Figure S3). A competitive behavior between the two different reactions has already been described in the literature for noble metals. Santiago et al. ${ }^{59}$ have demonstrated the competition for hydroxyl groups on the electrode surface between alcohol oxidation reactions and platinum oxide formation.

The voltammetric profile for $\mathrm{LaNiO}_{3}$ changes progressively from the first to the fifth cycle, experiencing some deactivation after consecutive potential cycling. As displayed Figure 2(b) the current response decreases steadily over time. In fact, after 10 cycles in the presence of glycerol, the electrode gets clearly blocked for GEOR and, if it is rinsed and taken to a cell free from glycerol, the contamination of the surface by adsorbed species is confirmed. Although in the first cycle it is possible to see a decrease in current due to the diminution of free active sites, the profile is essentially the same as before glycerol oxidation. After 10 cycles, the blank voltammogram is almost completely recovered (see Figure S4). This fact evinces that the deactivation phenomena is linked to the oxidation of glycerol that forms stable adsorbed species that accumulates on electrode at such extent that cannot be stripped off by oxidation or a reduction process. For Pt is well documented that the deactivation during alcohol oxidation is originated by the formation of adsorbed CO or other intermediates, such as acyl species. ${ }^{60,61} \mathrm{Re}-$ cently, Forslund et al. showed that $\mathrm{CO}$ does not adsorb on $\mathrm{LaNiO}_{3}$ showing that the GEOR on this perovskites follows a reaction mechanism that probably does not involve $\mathrm{CO} .{ }^{62}$
In fact, on perovskite catalysts the organic adsorption process occurs on partially oxidized sites. It is accepted that the transition metal is the reactive center for alcohol oxidation. ${ }^{63}$ For $\mathrm{LaNiO}_{3}$, nickel is the electroactive site as evidenced by the similarity of the $\mathrm{CV}$ profile with nickel electrodes. In this way, considering the potential window in which the GEOR takes pace, it is reasonable to suggest that $\mathrm{Ni}$ (III) is the active species for glycerol oxidation. In a similar way it was proposed for nickel electrodes that for the oxidation of alcohols ${ }^{64,65}$ and amines ${ }^{62,66}$, nickel oxide is considered to participate in the oxidation reaction by a direct or indirect process. For direct processes, after the electrochemical generation of $\mathrm{NiOOH}$, it is chemically reduced by the alcohol molecule. In indirect mechanisms, the electron transfer occurs by an electrochemical process between the adsorbed alcohol and the metal oxide. However, independent of the mechanism, Ni-hydroxide must be produced in order to activate the electrode ${ }^{65,67}$

Figure 3(a) presents the voltammetric profile for $\mathrm{LaCoO}_{3}$ which is in agreement with the literature ${ }^{68}$. Different than $\mathrm{LaNiO}_{3}$, no welldefined redox couple can be seen within the studied potential window. 'A slight current increase at $1.0 \mathrm{~V}$ is observed (i) probably related to high hydroxy group formation with $\mathrm{Co}$ (III). The oxygen evolution reaction, indicated as region (ii), starts at less positive potentials compared to $\mathrm{LaNiO}_{3}$. At region (iii) it is possible to see a discrete reduction process, possibly a reversible process related to the oxidation taking place at region (i). A similar process is observed for $\mathrm{Co}_{3} \mathrm{O}_{4}$ electrodes: in the positive scan the formation of $\mathrm{CoOOH}$ is observed and this specie is reduced during negative scan to $\mathrm{Co}_{3} \mathrm{O}_{4}{ }^{69}$

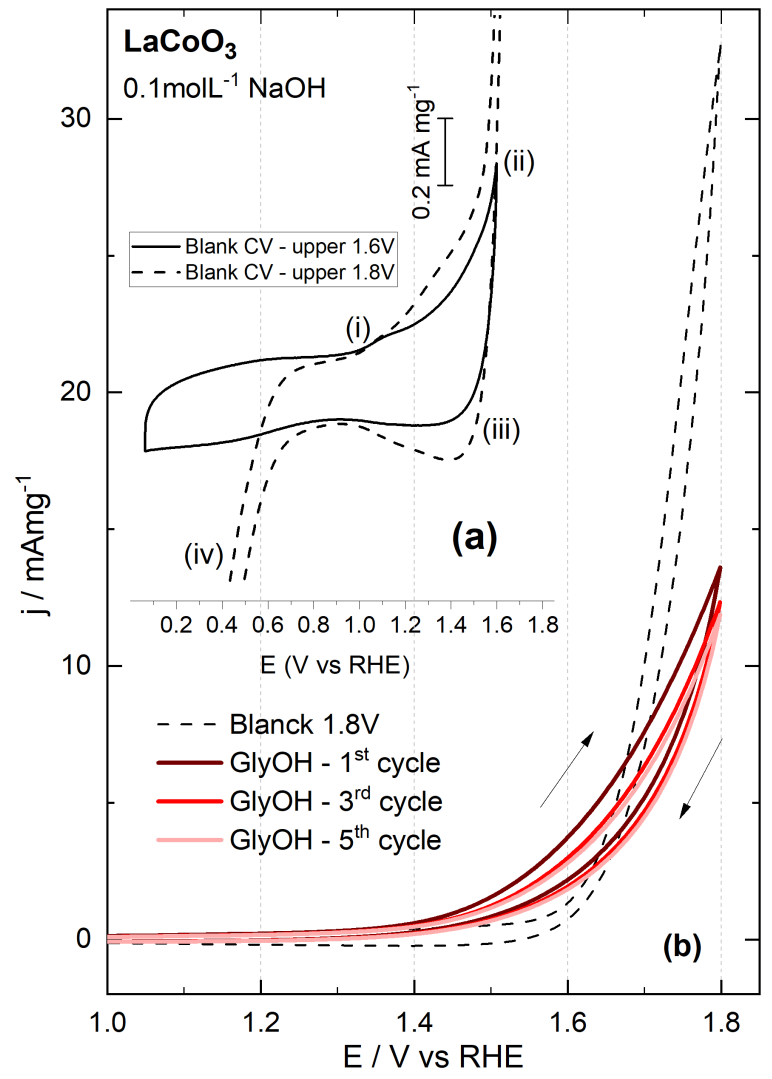

Figure 3: Voltammetric profile for $\mathrm{LaCoO}_{3}$ in the absence (a) and in the presence (b) of $0.1 \mathrm{molL}^{-1}$ glycerol in $0.1 \mathrm{molL}^{-1} \mathrm{NaOH}$ at $50 \mathrm{mVs}^{-1}$. (a) Blank voltammograms with different upper potentials: $1.6 \mathrm{~V}$ (solid line) and 1.8 V (dashed line). (b) Dash line shows the profile in the absence of glycerol and solid lines the $1^{\text {st }}, 3^{\text {rd }}$ and $5^{\text {th }}$ cycles of glycerol oxidation. Currents normalized by catalyst mass. Ohmic correction was applied. 
Figure 3(b) displays the cyclic voltammogram of $\mathrm{LaCoO}_{3}$ in $0.1 \mathrm{M}$ $\mathrm{NaOH}$ in the presence of glycerol. The consecutive recorded cyclic voltammograms are characterized by the absence of a hysteresis between the positive and negative potential scans as well as a slight decrease of the activity. Based on the shape of the voltammograms it is likely that the same process occurs in both scan directions. Thus, the lack of hysteresis suggests two possibilities about the GEOR mechanism on $\mathrm{LaCoO}_{3}$ : (i) it does not take place through the formation of strong adsorbed intermediates, or (ii) the surface within the potential window is active to oxidize all the adsorbed species.

Additionally, the onset potential for GEOR, ca. $1.27 \mathrm{~V}$, is shifted to lower values when compared to $\mathrm{LaNiO}_{3}$, probably due to the earlier formation of oxygenated species on $\mathrm{LaCoO}_{3}$ surface. Oliveira et al. observed the influence of $\mathrm{Co}$ in the study of $\mathrm{Ni} / \mathrm{C}$ and $\mathrm{NiCo} / \mathrm{C}$ nanoparticles activity ${ }^{11}$ towards GEOR. The results showed that the oxidation of glycerol is also related to the formation of O-containing species on CoNi nanoparticles surface. Since the formation of $\mathrm{CoOOH}$ occurs at lower potentials when compared to $\mathrm{Ni}$, the onset potential shifts accordingly.

The obtained current densities are comparable to those from $\mathrm{LaNiO}_{3}$ in the first cycle: the maximum current obtained for $\mathrm{LaNiO}_{3}$ was around $18 \mathrm{mAmg}^{-1}$ while $14 \mathrm{mAmg}^{-1}$ was obtained for $\mathrm{LaCoO}_{3}$. In the case of $\mathrm{LaCoO}_{3}$ no significant current decrease is observed during consecutive cycles showing a higher stability and poisoning resistance. For $\mathrm{LaCoO}_{3}$ the maximum current stabilizes around $13 \mathrm{mAmg}^{-1}$ while for $\mathrm{LaNiO}_{3}$ the current decreases continuously until being stabilized around $6 \mathrm{mAmg}^{-1}$. Another observation is that, as for $\mathrm{LaNiO}_{3}$ and $\mathrm{Pt}^{59}$, there might be a competition between GEOR and Oxygen Evolution Reaction (OER). The presence of glycerol inhibits the OER as can be observed comparing voltammetric profiles in the presence and absence of glycerol. When glycerol is present no bubble formation can be observed at high potentials and no reduction currents during negative scan, related to oxygen reduction, is observed. Data from Figures 2 and 3 are presented in Figure S3 in a different potential window to show the ORR region.

Although a high overpotential is needed to initiate glycerol oxidation when compared to noble metals as $\mathrm{Pt}, \mathrm{Au}$ and $\mathrm{Ag}^{6}$, GEOR on $\mathrm{LaNiO}_{3}$ shows high oxidation rates per mass of material and can be considered as a promising catalyst compared to nickel nanoparticles. Oliveira et al. ${ }^{11}$ reported a glycerol oxidation current density of approximately $70 \mathrm{~mA} / \mathrm{g}$ (metal mass) at $1.8 \mathrm{~V}$ when $\mathrm{Ni} / \mathrm{C}$ nanoparticles were used as catalyst. In this work, $\mathrm{LaNiO}_{3}$ catalyst presented a maximum current density of $18 \mathrm{~mA} / \mathrm{mg}$, a value ca. 250 times higher than the one reported for $\mathrm{Ni} / \mathrm{C} .^{11}$ We should keep in mind that the amount of the transition metal in the perovskite structure corresponds to only $24 \%$ of the total mass, which leads to a mass normalized current $(\mathrm{mA} / \mathrm{mg})$ for GEOR thousand times higher. ${ }^{11}$ This astonishing catalytic effect of $\mathrm{LaNiO}_{3}$ indicates that the transition metal in the perovskite does not respond sole to the observed phenomena, but together with the whole structure. This observation is in agreement with Forslund et al. ${ }^{62}$ who reported the enhanced catalytic effect towards urea oxidation when nickel is in the perovskite structure compared to nickel oxide, which exhibited poor activity. Additionally, the difference in superficial area, although not discussed in the reference, should also be considered.

Interpreting the GEOR in terms of in situ FTIR and online HPLC experiments

The products from GEOR were determined by online sample collection + HPLC analysis and FTIR in situ. On both materials the only reaction products detected by HPLC analysis were glycolate and formate (normalized chromatograms presented in Figure S5). Using the area obtained from the peaks and the calibration curves presented in Figure S1 it was possible to determine the concentration of both species in each sample, which are presented in Figure 4. It is possible to observe that similar concentrations of glycolate and formate are obtained when $\mathrm{LaNiO}_{3}$ is used as electrocatalyst, being the concentration of formic acid slightly higher. However, in the case of $\mathrm{LaCoO}_{3}$, different ratio is obtained. From Figure 4(b) it is possible to conclude that higher amounts of formate are formed, mainly at potentials higher than $1.7 \mathrm{~V}$. This difference in products ratio may indicate different abilities of both electrocatalysts to oxidize reaction intermediates. The activity of both catalysts to oxidize formic and glycolic acids will be discussed later.

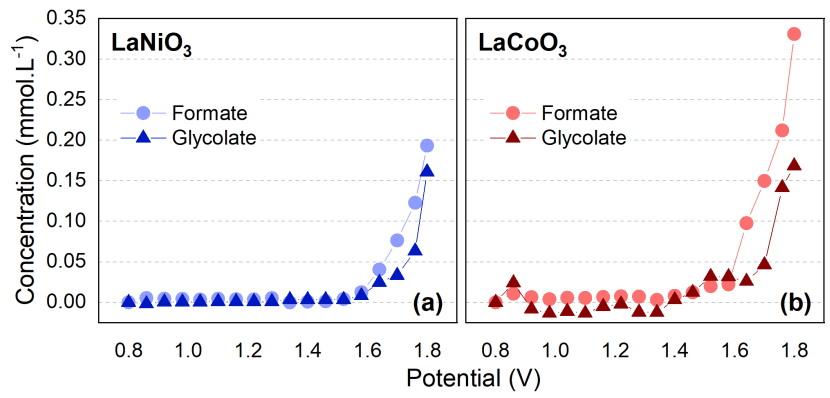

Figure 4: Formate (circle) and glycolate (triangle) formation from glycerol oxidation for (a) $\mathrm{LaNiO}_{3}$ and (b) $\mathrm{LaCoO}_{3}$. Concentration based on the integration of the corresponded HPLC peaks. Scan rate $1 \mathrm{mVs}^{-1}$ in a solution of $0.1 \mathrm{molL}^{-1}$ glycerol and $0.1 \mathrm{molL}^{-1}$ $\mathrm{NaOH}$.

An increase in product formation is observed from $1.4 \mathrm{~V}$ and $1.6 \mathrm{~V}$ for $\mathrm{LaCoO}_{3}$ and $\mathrm{LaNiO}_{3}$, respectively. These results are consistent with the results from cyclic voltammetry.

GEOR on both $\mathrm{LaNiO}_{3}$ and $\mathrm{LaCoO}_{3}$ was also investigated using FTIR. The spectra obtained at different potentials are presented in Figure 5. Figure 5(a) shows the results for $\mathrm{LaNiO}_{3}$ and it is possible to see the appearance of three bands $\left(1580 \mathrm{~cm}^{-1}, 1380 \mathrm{~cm}^{-1}\right.$ and $1350 \mathrm{~cm}^{-1}$ ) that increase at potentials higher than $1.4 \mathrm{~V}$. Considering the data available in the literature, formate presents defined bands at 1580,1380 and $1350 \mathrm{~cm}^{-1}$, corresponding to C-O stretching, $\mathrm{COO}$ rocking and $\mathrm{C}-\mathrm{O}$ stretching, respectively ${ }^{70,71}$. Glycolate has also bands at 1580 and $1075 \mathrm{~cm}^{-1}$, assigned to COO- stretching and C-O stretching, respectively ${ }^{72,73}$. Table S1 in the SI presents a list of the bands and respective assigned vibration modes. To investigate if these bands could also be assigned to other possible species, ATR experiments with the standard products were carried out. Solutions were prepared in concentration of $20 \mathrm{mmolL}^{-1}$ in $0.1 \mathrm{molL}^{-1} \mathrm{NaOH}$ and the results are presented in Figure S6.

The results for $\mathrm{LaCoO}_{3}$ are presented in Figure 5(b). Besides the same bands observed for $\mathrm{LaNiO}_{3}$, another band at $1308 \mathrm{~cm}^{-1}$ can also be seen. Considering the information in literature and standard spectra, it is possible to suggest that, in addition to formate and glycolate, oxalate is also formed. ${ }^{74,75}$ Based on the fact that oxalate was not detected by online HPLC analysis, one can infer that the concentration formed was low and not enough to be detected by HPLC. It is worth mention that the double peak seen at ca. $2340 \mathrm{~cm}^{-}$ ${ }^{1}$ is characteristic of atmospheric $\mathrm{CO}_{2}$. Since the reaction is taking place in alkaline medium, if $\mathrm{CO}_{2}$ was produced it would be converted to carbonate. 


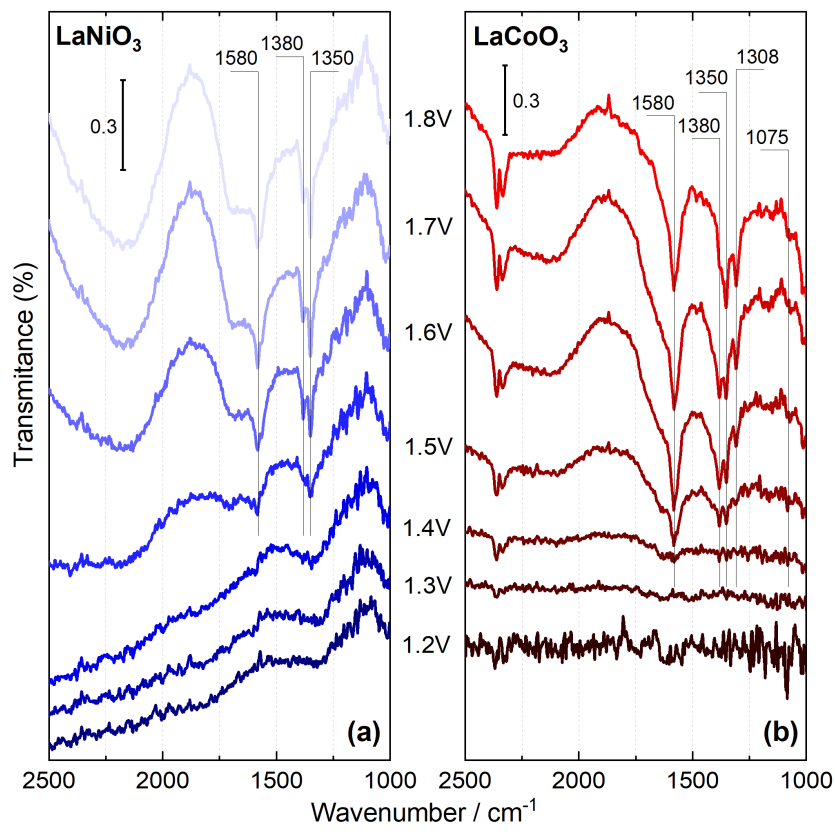

Figure 5: FTIR spectra for (a) $\mathrm{LaNiO}_{3}$ and (b) $\mathrm{LaCoO}_{3}$ obtained by in situ FITR in $0.1 \mathrm{molL}^{-1} \mathrm{NaOH}$ and $0.1 \mathrm{molL}^{-1}$ glycerol. Spectra are composed by 256 interferograms with $4 \mathrm{~cm}^{-1}$ of resolution. Reference spectra acquired at $0.8 \mathrm{~V}$.

The information provided by online HPLC and in situ FTIR suggest that glycerol is oxidized on both materials forming mainly glycolic and formic acids. On $\mathrm{LaCoO}_{3}$ oxalic acid can also be produced. However, despite the fact that the same products are formed on both catalysts, the ratio between formic and glycolic acids are different on $\mathrm{LaNiO}_{3}$ and $\mathrm{LaCoO}_{3}$.

To better understand GEOR pathway, glycolic and formic electrooxidation were investigated on both electrocatalysts. As can be observed in Figure S7 of the SI, neither of the materials can oxidize formic acid, but they are active to oxidize glycolic acid, being $\mathrm{LaCoO}_{3}$ the more active. Considering the results obtained from HPLC and FTIR, it is reasonable to suggest that the oxidation of glycolic acid generates formic acid on both electrodes and oxalic acid on $\mathrm{LaCoO}_{3}$. In this way, GEOR probably produces equally amounts of formic and glycolic acids, but glycolic acid is further oxidized to formic acid and, on $\mathrm{LaCoO}_{3}$, also oxalic acid.

Based on the presented results, a GEOR pathway can be suggested: (i) glycerol is oxidized on both $\mathrm{LaNiO}_{3}$ and $\mathrm{LaCoO}_{3}$ to formic and glycolic acids, (ii) glycolic acid can be oxidized to formic acid on both catalysts and (iii) to oxalic acid on $\mathrm{LaCoO}_{3}$. This proposed mechanism is represented in Scheme 1. Apparently, formic acid is the final product of GEOR on both electrocatalysts not been further oxidized to $\mathrm{CO}_{2}$. Similar result was shown by Han et al. ${ }^{76}$ for cobalt-based spinel oxide.

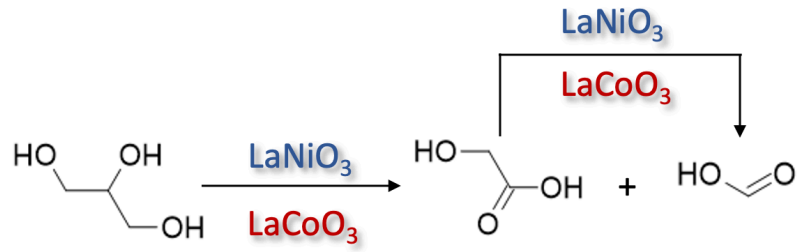

Glycerol

Glycolic Acid

Formic Acid<smiles>CC(C)(OC(=O)COC(=O)C(=O)O)C(=O)O</smiles>

Scheme 1: Reaction pathway with glycerol oxidation products on $\mathrm{LaNiO}_{3}$ and $\mathrm{LaCoO}_{3}$.

\section{CONCLUSION}

The presented results suggest that $\mathrm{LaNiO}_{3}$ and $\mathrm{LaCoO}_{3}$ have catalytic activity towards glycerol electrooxidation. Also, the formation of hydroxy oxide species on the electrode surface is mandatory to enable the GEOR. The oxidation currents (normalized by catalyst mass) are much higher, ca. 250 times higher, than those presented in the literature for $\mathrm{Ni} / \mathrm{C}$ nanoparticles. Substitution of the transition metal in the perovskite structure can promote different behaviors of catalyst in terms of current, onset potential and resistance to poisoning. $\mathrm{LaCoO}_{3}$ presented a lower onset potential and higher resistance to surface poisoning. The products of glycerol electrooxidation on both materials are mainly glycolic and formic acids, being formic acid the final reaction product. On $\mathrm{LaCoO}_{3}$ a side reaction can take place generating oxalic acid from glycolic acid readsorption and further oxidation.

These findings open up a series of new possibilities considering the use of perovskite oxides as electrocatalysts for the conversion of biomass to chemicals.

\section{ASSOCIATED CONTENT}

Supporting Information.

This information is available free of charge on the ACS Publications website

\section{AUTHOR INFORMATION}

Corresponding Author

* email: janaina.garcia@ufabc.edu.br

\section{ACKNOWLEDGMENT}

The authors thank FAPESP through projects 2018/06677-6, 2018/10292-2, 2016/01365-0, 2017/11986-5, 2018/20952-0 and 2019/07449-0 and Shell and the strategic importance of the support given by ANP (Brazil's National Oil, Natural Gas and Biofuels Agency) through the R\&D levy regulation. This study was financed in part by the Coordenação de Aperfeiçoamento de Pessoal de Nível Superior - Brasil (CAPES).

\section{REFERENCES}

Coutanceau, C.; Baranton, S. S. Electrochemical Conversion of Alcohols for Hydrogen Production: A Short Overview. Wiley Interdiscip. Rev. Energy Environ. 2016, 5 (4), 388-400. https://doi.org/10.1002/wene.193. 
(2) Simões, M.; Baranton, S.; Coutanceau, C. Electrochemical Valorisation of Glycerol. ChemSusChem 2012, 5 (11), 21062124. https://doi.org/10.1002/cssc.201200335.

(3) Dodekatos, G.; Schünemann, S.; Tüysüz, H. Recent Advances in Thermo-, Photo-, and Electrocatalytic Glycerol Oxidation. ACS Catal. 2018, 8 (7), 6301-6333. https://doi.org/10.1021/acscatal.8b01317.

(4) Pagliaro, M.; Rossi, M. The Future of Glycerol. Focus Catal. 2008, $2008 \quad$ (6), $\quad 8 . \quad$ https://doi.org/10.1016/S13514180(08)70291-5.

(5) Martins, C. A.; Fernández, P. S.; Camara, G. A. Alternative Uses for Biodiesel Byproduct: Glycerol as Source of Energy and High Valuable Chemicals; Springer, Cham, 2018; pp 159-186. https://doi.org/10.1007/978-3-319-73552-8_7.

(6) Angelucci, C. A.; Sp, S. A. Glycerol Electrooxidation on Noble Metal Electrode Surfaces. 2018, 643-650. https://doi.org/10.1016/B978-0-12-409547-2.13330-X.

Garcia, A. C.; Kolb, M. J.; Van Nierop Y Sanchez, C.; Vos, J.; Birdja, Y. Y.; Kwon, Y.; Tremiliosi-Filho, G.; Koper, M. T. M. Strong Impact of Platinum Surface Structure on Primary and Secondary Alcohol Oxidation during Electro-Oxidation of Glycerol. ACS Catal. 2016, 6 (7), 4491-4500. https://doi.org/10.1021/acscatal.6b00709.

(8) Kwon, Y.; Hersbach, T. J. P. P.; Koper, M. T. M. M. ElectroOxidation of Glycerol on Platinum Modified by Adatoms: Activity and Selectivity Effects. Top. Catal. 2014, 57 (14-16), 1272-1276. https://doi.org/10.1007/s11244-014-0292-6.

(9) Suzuki, N. Y.; Santiago, P. V. B.; Galhardo, T. S.; Carvalho, W. A.; Souza-Garcia, J.; Angelucci, C. A. Insights of Glycerol Electrooxidation on Polycrystalline Silver Electrode. $J$ Electroanal. Chem. 2016, 2-6. https://doi.org/10.1016/j.jelechem.2016.02.020.

(10) Sandrini, R. M. L. M.; Sempionatto, J. R.; Tremiliosi-Filho, G.; Herrero, E.; Feliu, J. M.; Souza-Garcia, J.; Angelucci, C. A. Electrocatalytic Oxidation of Glycerol on Platinum Single Crystals in Alkaline Media. ChemElectroChem 2019. https://doi.org/10.1002/celc.201900311.

(11) Oliveira, V. L.; Morais, C.; Servat, K.; Napporn, T. W.; Tremiliosi-Filho, G.; Kokoh, K. B. Glycerol Oxidation on Nickel Based Nanocatalysts in Alkaline Medium - Identification of the Reaction Products. J. Electroanal. Chem. 2013, 703, 56-62. https://doi.org/10.1016/j.jelechem.2013.05.021.

(12) Habibi, B.; Delnavaz, N. Electrooxidation of Glycerol on Nickel and Nickel Alloy ( $\mathrm{Ni}-\mathrm{Cu}$ and $\mathrm{Ni}-\mathrm{Co})$ Nanoparticles in Alkaline Media. RSC Adv. 2016, 6 (38), 31797-31806. https://doi.org/10.1039/C5RA26006J.

(13) Ashok, A.; Kumar, A.; Ponraj, J.; Mansour, S. A.; Tarlochan, F. Single Step Synthesis of Porous $\mathrm{NiCoO} 2$ for Effective Electrooxidation of Glycerol in Alkaline Medium. $J$. Electrochem. Soc. 2018, 165 (15), J3301-J3309. https://doi.org/10.1149/2.0401815jes.

(14) Sun, S.; Sun, L.; Xi, S.; Du, Y.; Anu Prathap, M. U.; Wang, Z.; Zhang, Q.; Fisher, A.; Xu, Z. J. Electrochemical Oxidation of C3 Saturated Alcohols on $\mathrm{Co} 3 \mathrm{O} 4$ in Alkaline. Electrochim. Acta 2017, 228 ,

183-194. https://doi.org/10.1016/j.electacta.2017.01.086.

(15) Dantas, L. M. F.; DeSouza, A. P. R.; Castro, P. S.; Paixão, T. R. L. C.; Bertotti, M. SECM Studies on the Electrocatalytic Oxidation of Glycerol at Copper Electrodes in Alkaline Medium. Electroanalysis $\quad \mathbf{2 0 1 2}, \quad 24 \quad$ (8), $\quad 1778-1782$. https://doi.org/10.1002/elan.201200144.

(16) Xu, C.; Tian, Z.; Shen, P.; Jiang, S. P. Oxide (CeO2, NiO, Co3O4 and $\mathrm{Mn} 3 \mathrm{O} 4)-$ Promoted $\mathrm{Pd} / \mathrm{C}$ Electrocatalysts for Alcohol Electrooxidation in Alkaline Media. Electrochim. Acta 2008, 53 (5), 2610-2618. https://doi.org/10.1016/j.electacta.2007.10.036.

(17) Su, Y. Z.; Xu, Q. Z.; Zhong, Q. S.; Zhang, C. J.; Shi, S. T.; Xu, C. W. Oxide (Co3O4, NiO, Mn3O4, MgO) Promoted $\mathrm{Au} / \mathrm{C}$ Catalyst for Glycerol Electrooxidation in Alkaline Medium. Mater. Res. Bull. 2015, 64, 301-305. https://doi.org/10.1016/j.materresbull.2015.01.007.

(18) Peña, M. A.; Fierro, J. L. G. Chemical Structures and Performance of Perovskite Oxides. Chem. Rev. 2001, 101 (7), 1981-2017. https://doi.org/10.1021/cr980129f.

(19) Zhu, H.; Zhang, P.; Dai, S. Recent Advances of LanthanumBased Perovskite Oxides for Catalysis. ACS Catal. 2015, 5,
6370-6385. https://doi.org/10.1021/acscatal.5b01667.

(20) Xu, X.; Zhong, Y.; Shao, Z. Double Perovskites in Catalysis, Electrocatalysis, and Photo(Electro)Catalysis. Trends Chem. 2019, 11 (4), 410-424 https://doi.org/10.1016/j.trechm.2019.05.006.

(21) Snaith, H. J. Perovskites: The Emergence of a New Era for LowCost, High-Efficiency Solar Cells. J. Phys. Chem. Lett. 2013, 4 (21), 3623-3630. https://doi.org/10.1021/jz4020162.

(22) Xu, J.; Chen, C.; Han, Z.; Yang, Y.; Li, J.; Deng, Q. Recent Advances in Oxygen Electrocatalysts Based on Perovskite Oxides. Nanomaterials 2019, 9 (1161), 1-19. https://doi.org/10.3390/nano9081161.

(23) Kubicek, M.; Bork, A. H.; Rupp, J. L. M. Perovskite Oxides - a Review on a Versatile Material Class for Solar-to-Fuel Conversion Processes. J. Mater. Chem. A 2017, 5 (24), 1198312000. https://doi.org/10.1039/C7TA00987A.

(24) Royer, S.; Duprez, D. Catalytic Oxidation of Carbon Monoxide over Transition Metal Oxides. ChemCatChem 2011, 3 (1), 24-65. https://doi.org/10.1002/cctc.201000378.

(25) Viswanathan, B. CO Oxidation and NO Reduction on Perovskite Oxides. Catal. Rev. 1992, 34 (4), 337-354. https://doi.org/10.1080/01614949208016316.

(26) Song, K.-S.; Xing Cui, H.; Kim, S. D.; Kang, S.-K. Catalytic Combustion of $\mathrm{CH} 4$ and $\mathrm{CO}$ on La1-xMxMnO3 Perovskites. Catal. Today 1999, 47 (1-4), 155-160. https://doi.org/10.1016/S0920-5861(98)00295-8.

(27) Tascón, L. G. T. J. L. G. F. and J. M. D. Structure and Reactivity of Perovskite-Type Oxides. Adv. Catal. 2006, 36, 237-328.

(28) Iwakuni, H.; Shinmyou, Y.; Yano, H.; Matsumoto, H.; Ishihara, T. Direct Decomposition of NO into N2 and O2 on BaMnO3Based Perovskite Oxides. Appl. Catal. B Environ. 2007, 74 (34), 299-306. https://doi.org/10.1016/j.apcatb.2007.02.020.

Imanaka, N.; Masui, T. Advances in Direct NOx Decomposition Catalysts. Appl. Catal. A Gen. 2012, 431-432, 1-8. https://doi.org/10.1016/j.apcata.2012.02.047.

(30) Watson, P. R.; Somorjai, G. A. The Formation of OxygenContaining Organic Molecules by the Hydrogenation of Carbon Monoxide Using a Lanthanum Rhodate Catalyst. J. Catal. 1982 74 (2), 282-295. https://doi.org/10.1016/0021-9517(82)90034-3.

(31) Fierro, J. L. G. Hydrogenation of Carbon Oxides over PerovskiteType Oxides. Catal. Rev. 1992, 34 (4), 321-336. https://doi.org/10.1080/01614949208016315.

(32) Wu, G.; Li, S.; Zhang, C.; Wang, T.; Gong, J. Glycerol Steam Reforming over Perovskite-Derived Nickel-Based Catalysts. Appl. Catal. B Environ. 2014, 144 (1), 277-285. https://doi.org/10.1016/j.apcatb.2013.07.028.

(33) Ramesh, S.; Yang, E.-H. H.; Jung, J. S.; Moon, D. J. Copper Decorated Perovskite an Efficient Catalyst for Low Temperature Hydrogen Production by Steam Reforming of Glycerol. Int. J Hydrogen Energy 2015, 40 (35), 11428-11435. https://doi.org/10.1016/j.ijhydene.2015.02.013.

(34) Bockris, J. O. The Electrocatalysis of Oxygen Evolution on Perovskites. J. Electrochem. Soc. 1984, 131 (2), 290. https://doi.org/10.1149/1.2115565.

(35) Savinell, R. F. Oxygen-Reduction Catalysts: Picking Perovskites Nat. Chem. 2011, 3 (7), 501-502. https://doi.org/10.1038/nchem.1083.

(36) Suntivich, J.; Gasteiger, H. A.; Yabuuchi, N.; Nakanishi, H.; Goodenough, J. B.; Shao-Horn, Y. Design Principles for OxygenReduction Activity on Perovskite Oxide Catalysts for Fuel Cells and Metal-Air Batteries. Nat. Chem. 2011, 3 (7), 546-550. https://doi.org/10.1038/nchem.1069.

(37) Hong, W. T.; Risch, M.; Stoerzinger, K. A.; Grimaud, A.; Suntivich, J.; Shao-Horn, Y. Toward the Rational Design of NonPrecious Transition Metal Oxides for Oxygen Electrocatalysis. Energy Environ. Sci. 2015, 8 (5), 1404-1427. https://doi.org/10.1039/c4ee03869j.

(38) Hwang, J.; Rao, R. R.; Giordano, L.; Katayama, Y.; Yu, Y.; ShaoHorn, Y. Perovskites in Catalysis and Electrocatalysis. Science 2017, 358 (6364), 751-756 https://doi.org/10.1126/science.aam7092.

(39) Mefford, J. T.; Rong, X.; Abakumov, A. M.; Hardin, W. G.; Dai, S.; Kolpak, A. M.; Johnston, K. P.; Stevenson, K. J. Water Electrolysis on La1-xSrxCoO3- $\delta$ Perovskite Electrocatalysts. Nat. Commun. 2016, 7. https://doi.org/10.1038/ncomms11053. 
Retuerto, M.; Pereira, A. G.; Pérez-Alonso, F. J.; Peña, M. A.; Fierro, J. L. G.; Alonso, J. A.; Fernández-Díaz, M. T.; Pascual, L.; Rojas, S. Structural Effects of LaNiO3 as Electrocatalyst for the Oxygen Reduction Reaction. Appl. Catal. B Environ. 2017, 203, 363-371. https://doi.org/10.1016/j.apcatb.2016.10.016.

(41) Hardin, W. G.; Me, J. T.; Slanac, D. A.; Patel, B. B.; Wang, X.; Dai, S.; Zhao, X.; Ruo, R. S.; Johnston, K. P.; Stevenson, K. J. Tuning the Electrocatalytic Activity of Perovskites through Active Site Variation and Support Interactions. 2014.

(42) Rossmeisl, J.; Qu, Z.-W.; Zhu, H.; Kroes, G.-J.; Nørskov, J. K. Electrolysis of Water on Oxide Surfaces. J. Electroanal. Chem. 2007, $607 \quad(1-2), \quad 83-89$. https://doi.org/10.1016/j.jelechem.2006.11.008.

(43) Stoerzinger, K. A.; Qiao, L.; Biegalski, M. D.; Shao-Horn, Y. Orientation-Dependent Oxygen Evolution Activities of Rutile IrO 2 and RuO 2. J. Phys. Chem. Lett. 2014, 5 (10), 1636-1641. https://doi.org/10.1021/jz500610u.

(44) Royer, S.; Duprez, D.; Can, F.; Courtois, X.; Batiot-Dupeyrat, C.; Laassiri, S.; Alamdari, H. Perovskites as Substitutes of Noble Metals for Heterogeneous Catalysis: Dream or Reality. Chem. Rev. 2014, $114 \quad$ (20), 10292-10368. https://doi.org/10.1021/cr500032a.

(45) Lan, A.; Mukasyan, A. S. Perovskite-Based Catalysts for Direct Methanol Fuel Cells. J. Phys. Chem. C 2007, 111 (26), 9573 9582. https://doi.org/10.1021/jp067343p.

(46) Aman, D.; Radwan, D.; Ebaid, M.; Mikhail, S.; Steen, E. Van. Comparing Nickel and Cobalt Perovskites for Steam Reforming of Glycerol. Mol. Catal. 2018, 452 (March), 60-67. https://doi.org/10.1016/j.mcat.2018.03.022.

(47) Garcia, J. Perovskitas Preparadas Pelo Método Do Citrato Como Catalisadores Para a Reação de Redução de NO Com CO. 2011.

(48) Galal, A.; Atta, N. F.; Ali, S. M. Optimization of the Synthesis Conditions for LaNiO 3 Catalyst by Microwave Assisted Citrate Method for Hydrogen Production. Appl. Catal. A Gen. 2011, 409-410, 202-208. https://doi.org/10.1016/j.apcata.2011.10.005.

(49) Rao, K. J.; Vaidhyanathan, B.; Ganguli, M.; Ramakrishnan, P. A Synthesis of Inorganic Solids Using Microwaves. Chem. Mater 1999, 11 (4), 882-895. https://doi.org/10.1021/cm9803859.

(50) Iwasita, T.; Nart, F. C. In Situ Infrared Spectroscopy At Electrochemical Interfaces. Pergamon Prog. Surf. Sci. 1997, 55 (4), 271-340. https://doi.org/10.1016/S0079-6816(97)00032-4

(51) Kwon, Y.; Koper, M. T. M. Combining Voltammetry with HPLC: Application to Electro-Oxidation of Glycerol. Anal. Chem. 2010, 82 (13), 5420-5424. https://doi.org/10.1021/ac101058t.

(52) Retuerto, M.; Pereira, A. G.; Pérez-alonso, F. J.; Miguel, A. Fierro, J. L. G.; Alonso, J. A.; Pascual, L. Structural Effects of LaNiO 3 as Electrocatalyst for the Oxygen Reduction Reaction. 6-9.

(53) Oliveira, V. L.; Morais, C.; Servat, K.; Napporn, T. W.; Olivi, P.; Kokoh, K. B.; Tremiliosi-Filho, G. Kinetic Investigations of Glycerol Oxidation Reaction on Ni/C. Electrocatalysis 2015, 6 (5), 447-454. https://doi.org/10.1007/s12678-015-0261-2.

(54) Houache, M. S. E.; Cossar, E.; Ntais, S.; Baranova, E. A Electrochemical Modification of Nickel Surfaces for Efficient Glycerol Electrooxidation. J. Power Sources 2018, 375, 310-319. https://doi.org/10.1016/j.jpowsour.2017.08.089.

(55) Tehrani, R. M. A.; AbGhani, S. The Nanocrystalline Nickel with Catalytic Properties on Methanol Oxidation in Alkaline Medium. $\begin{array}{lllll}\text { Fuel Cells 2009, } & 9 & \text { (5), 579-587. }\end{array}$ https://doi.org/10.1002/fuce.200800122.

(56) El-Shafei, A. A. Electrocatalytic Oxidation of Methanol at a Nickel Hydroxide/Glassy Carbon Modified Electrode in Alkaline Medium. J. Electroanal. Chem. 1999, 471 (2), 89-95. https://doi.org/10.1016/S0022-0728(99)00235-1.

(57) Hardin, W. G.; Slanac, D. A.; Wang, X.; Dai, S.; Johnston, K. P.; Stevenson, K. J. Highly Active, Nonprecious Metal Perovskite Electrocatalysts for Bifunctional Metal-Air Battery Electrodes. $J$. Phys. Chem. Lett. 2013, 4 (8), 1254-1259. https://doi.org/10.1021/jz400595z.

(58) Busó-Rogero, C.; Herrero, E.; Feliu, J. M. Ethanol Oxidation on Pt Single-Crystal Electrodes: Surface-Structure Effects in Alkaline Medium. ChemPhysChem 2014, 15 (10), 2019-2028. https://doi.org/10.1002/cphc.201402044

(59) Santiago, P. V. B. V. B.; Oliveira, R. A. G. A. G.; Roquetto, J. M. M.; Akiba, N.; Gaubeur, I.; Angelucci, C. A. A.; Souza-Garcia,
J.; Feliu, J. M. M. Oxide Formation as Probe to Investigate the Competition between Water and Alcohol Molecules for $\mathrm{OH}$ Species Adsorbed on Platinum. Electrochim. Acta 2019, 317, 694-700. https://doi.org/10.1016/j.electacta.2019.06.037.

(60) Sandrini, R. M. L. M.; Sempionatto, J. R.; Herrero, E.; Feliu, J. M.; Souza-Garcia, J.; Angelucci, C. A. Mechanistic Aspects of Glycerol Electrooxidation on $\mathrm{Pt}(111)$ Electrode in Alkaline Media. Electrochem. commun. 2018, 86 (November 2017), 149152. https://doi.org/10.1016/j.elecom.2017.11.027.

(61) Schnaidt, J.; Heinen, M.; Jusys, Z.; Behm, R. J. Electro-Oxidation of Ethylene Glycol on a Pt-Film Electrode Studied by Combined in Situ Infrared Spectroscopy and Online Mass Spectrometry. $J$. Phys. Chem. C 2012, 116 (4), 2872-2883. https://doi.org/10.1021/jp208162q.

(62) Forslund, R. P.; Mefford, J. T.; Hardin, W. G.; Alexander, C. T.; Johnston, K. P.; Stevenson, K. J. Nanostructured LaNiO3 Perovskite Electrocatalyst for Enhanced Urea Oxidation. ACS Catal. 2016, 6 (8), 5044-5051 https://doi.org/10.1021/acscatal.6b00487.

(63) White, J. H. Perovskite Anode Electrocatalysis for Direct Methanol Fuel Cells. J. Electrochem. Soc. 1993, 140 (8), 2167. https://doi.org/10.1149/1.2220791.

(64) Machado, A. S.; Ticianelli, E. A.; Bott-neto, J. L.; Martins, T. S.; Box, P. O. Electrocatalytic Oxidation of Methanol, Ethanol, and Glycerol on Ni ( $\mathrm{OH}) 2$ Nanoparticles Encapsulated with Poly [ $\mathrm{Ni}$ ( Salen )] Film. 2019. https://doi.org/10.1021/acsami.9b08441.

(65) Vértes, G.; Horányi, G. Some Problems of the Kinetics of the Oxidation of Organic Compounds at Oxide-Covered Nickel Electrodes. J. Electroanal. Chem. 1974, 52 (1), 47-53. https://doi.org/10.1016/S0022-0728(74)80100-2.

(66) Vedharathinam, V.; Botte, G. G. Direct Evidence of the Mechanism for the Electro-Oxidation of Urea on $\mathrm{Ni}(\mathrm{OH}) 2$ Catalyst in Alkaline Medium. Electrochim. Acta 2013, 108, 660665. https://doi.org/10.1016/j.electacta.2013.06.137.

(67) Fleischmann, M.; Korinek, K.; Pletcher, D. The Oxidation of Organic Compounds at a Nickel Anode in Alkaline Solution. $J$. Electroanal. Chem. 1971, 31 (1), 39-49. https://doi.org/10.1016/S0022-0728(71)80040-2.

(68) Sivakumar, M.; Sakthivel, M.; Chen, S. M.; Veerakumar, P.; Liu, S. Bin. Sol-Gel Synthesis of Carbon-Coated $\mathrm{LaCoO} 3$ for Effective Electrocatalytic Oxidation of Salicylic Acid ChemElectroChem 2017, 4 (4), 935-940. https://doi.org/10.1002/celc.201600714.

(69) FLEISCHMANN, M.; KORINEK, K.; PLETCHER, D. The Kinetics and Mechanism of the Oxidation of Amines and Alcohols at Oxide-Covered Nickel, Silver, Copper and Cobalt Electrodes. J. Chem. Soc. Perkin Trans. 2 1972, 10, 1396-1403. GOPAL, P. Evidence for Production of Surface Formate upon Direct Reaction of $\mathrm{CO}$ with Alumina and Magnesia. J. Catal. 1987, 105 (2), 366-372. https://doi.org/10.1016/00219517(87)90066-2

(71) Ito, K.; Bernstein, H. J. THE VIBRATIONAL SPECTRA OF THE FORMATE, ACETATE, AND OXALATE IONS. Can. $J$ Chem. 1956, 34 (2), 170-178. https://doi.org/10.1139/v56-021.

(72) Christensen, P. A.; Hamnett, A. The Oxidation of Ethylene Glycol at a Platinum Electrode in Acid and Base. An in Situ FTIR Study. J. Electroanal. Chem. 1989, 260 (2), 347-359. https://doi.org/10.1016/0022-0728(89)87149-9.

(73) Ferreira, R. S.; Janete Giz, M.; Camara, G. A. Influence of the Local PH on the Electrooxidation of Glycerol on PalladiumRhodium Electrodeposits. J. Electroanal. Chem. 2013, 697, 1520. https://doi.org/10.1016/j.jelechem.2013.03.007.

(74) de Souza, N. E.; Gomes, J. F.; Tremiliosi-Filho, G. Reactivity of 3-Carbon-Atom Chain Alcohols on Gold Electrode: A Comparison to Understand the Glycerol Electro-Oxidation. $J$. Electroanal. Chem. 2017, 800, 106-113. https://doi.org/10.1016/j.jelechem.2016.08.019.

(75) Li, F.; Koopal, L.; Tan, W. Roles of Different Types of Oxalate Surface Complexes in Dissolution Process of Ferrihydrite Aggregates. Sci. Rep. 2018, 8 (1), 1-13. https://doi.org/10.1038/s41598-018-20401-5.

(76) Han, X.; Sheng, H.; Yu, C.; Walker, T. W.; Huber, G. W.; Qiu, J.; Jin, S. Electrocatalytic Oxidation of Glycerol to Formic Acid by CuCo $2 \mathrm{O} 4$ Spinel Oxide Nanostructure Catalysts. ACS Catal. 2020, 6741-6752. https://doi.org/10.1021/acscatal.0c01498. 
For Table of Contents Only

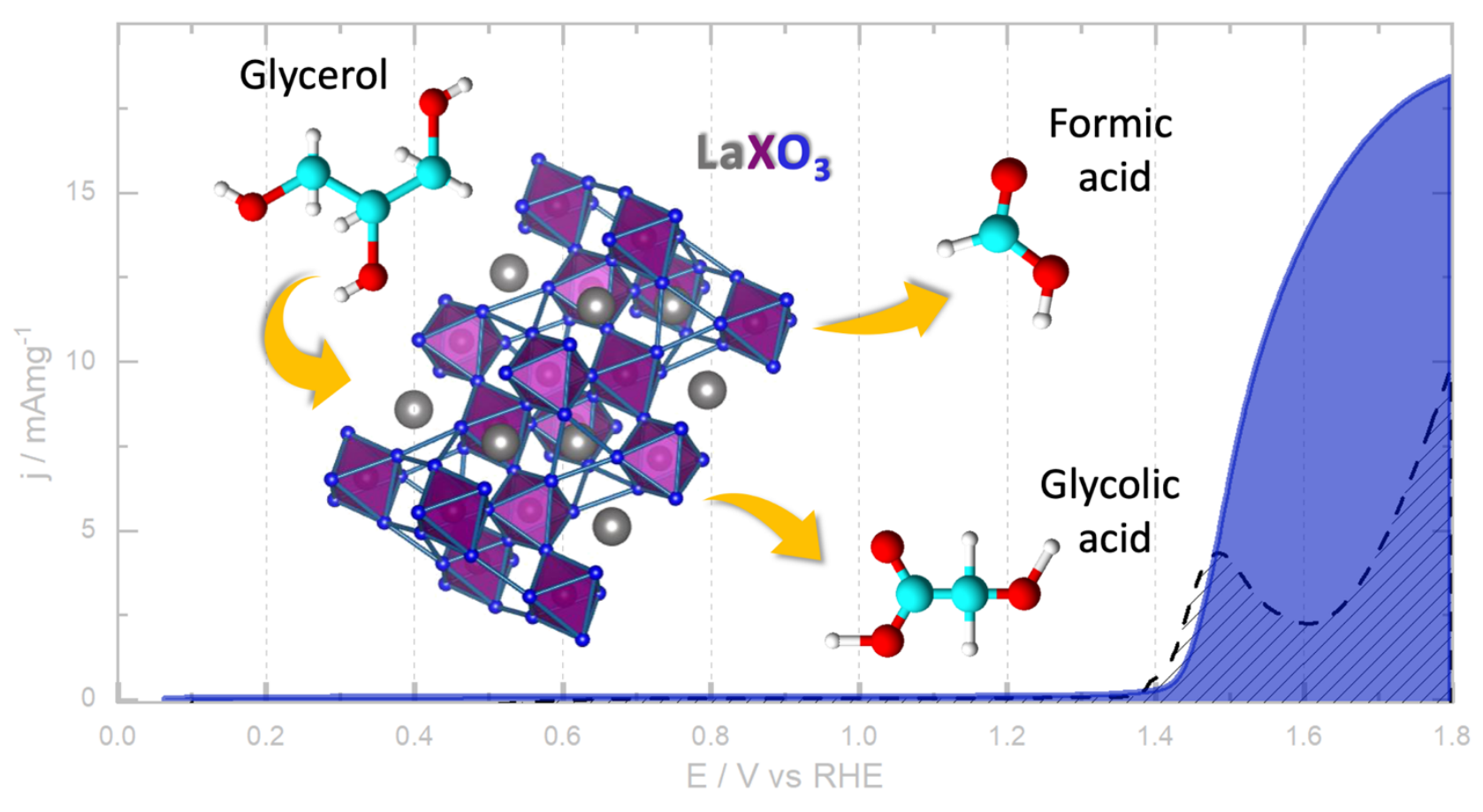

